\title{
Discounting the Cost of Future Care for Persons with Disabilities
}

\author{
David Strauss, Robert Shavelle, Christopher Pflaum, and \\ Christopher Bruce
}

\section{Introduction}

The cost of future care of the severely disabled is important to both the legal system and the insurance industry. It is commonplace for juries to award large sums to the traumatically injured, to fund their future medical care and assistance with activities of daily life. Insurers specializing in writing life annuities for the disabled, known as structured settlements, base their rates for these products on calculations similar to those of forensic economists. Some long-term care facilities that offer lifetime care to the profoundly disabled provide an annuity option as a means of payment.

The availability of insurance products to the disabled is critical. Without a market to bear the risk that the individual will live longer than expected, many disabled will outlive their life-care funding and become dependent on their families or the state. For these products to be widely available, those who would provide them must be able to forecast future payments to a portfolio of risks with a reasonable degree of statistical certainty.

In this paper we are concerned with the expected present value (EPV) of future costs corresponding to a given life expectancy. At issue is the effect of using different methods of deriving a life table. Specifically, we compare the estimated costs using the rated life and ratio methods to that found using a more empirically supported actuarial analysis. Compared to the latter, the approximation methods yield estimates of the EPV that are often significantly overstated.

Surprisingly, the issue has not been well covered in the literature. Slesnick and Thornton (1997) describe one approximate procedure, and develop a set of life tables from it, but do not discuss the procedure's accuracy. For the general population, Ben-Zion and Reddall (1985) compare the "life expectancy approach" (the assumption that the survival time is exactly equal to the life expectancy) to the use of life tables and find that the former significantly overstates the present value. This inequality had previously been noted by Jordan (1967), who remarked that it is a "widespread misconception" that the two quantities are equal. No one, however, has examined the discrepancy between approximate methods (based on modifications of general population life tables)

*David Strauss and Robert Shavelle, Life Expectancy Project, San Francisco CA; Christopher Pflaum, Spectrum Economics, Overland Park, KS; Christopher Bruce, Economica Ltd., Calgary, Alberta, Canada.

${ }^{1}$ This is for the case of an immediate annuity, with a net discount rate greater than zero. 
and the analysis of the appropriate cohorts for populations with reduced life expectancy.

\section{Estimating Future Care Costs}

There are three components in the calculation of the expected present value (EPV) of the cost of lifetime care:

1. The dollar amount $d(t)$ to provide the care at time, or year, t. The amount will be specified in detail in the life-care plan. The function $d(t)$ may be increasing, decreasing or "lumpy." In many instances $d(\mathrm{t})$ will reflect an assumed growth function specifying the rate at which expenses are expected to grow in the future. The rate of growth is usually, though not necessarily, lower than the rate of discount.

2. A discount function $\mathrm{g}(\mathrm{t})$ specifying the present value of a unit payment at time $t$ in the future. Though there is some debate over the appropriate form for the discount function, all that is assumed here is that $\mathrm{g}$ is a monotonically decreasing function of $\mathrm{t}$ (i.e., the later the payment, the smaller its present value).

3. The probability $\mathrm{S}(\mathrm{t})$ that the plaintiff survives to time $\mathrm{t}$, as measured from time of trial or settlement. Formally, $\mathrm{S}(\mathrm{t})$ is the complement of the probability distribution function $\mathrm{F}(\mathrm{t})$. That is, $\mathrm{F}(\mathrm{t})=1-\mathrm{S}(\mathrm{t})$ is the chance that the plaintiff dies no later than time $t$.

We will take the time parameter $\mathrm{t}$ as being discrete here, and thus work with sums rather than integrals. The discrete formulation is, of course, the one used in most numerical work.

Let $h(t)$ be the present value of the stream of payments up to time $t$ :

$$
\mathrm{h}(\mathrm{t})=\Sigma \mathrm{g}(\mathrm{i}) \mathrm{d}(\mathrm{i}),
$$

the sum being over i in $[0, t]$. The product $g(i) d(i)$ may be regarded as a net discount factor, and will in the majority of cases be a decreasing function. This will be so if $d(t)$ is constant, or increases more slowly than $g(t)$ declines. The function $\mathrm{h}(\mathrm{t})$ is then convex, which proves significant in what follows.

When the functions $g$ and $d$ are specified, the expected present value (EPV) of the cost of future care is obtained by multiplying the discounted cost of care for time $t$ by the chance that the person is alive at time $t$ to need the care, and summing over $t$. That is,

$$
\mathrm{EPV}=\Sigma \mathrm{g}(\mathrm{t}) \mathrm{d}(\mathrm{t}) \mathrm{S}(\mathrm{t}),
$$

the sum being over all $t>0$. When the injury is not one that reduces the life expectancy, the survival distribution $\mathrm{S}(\mathrm{t})$ is that of the general population and can be obtained from an ordinary life table (Schoen, 1988). Specifically, the probability of surviving an additional $\mathrm{t}$ years from the current age $\mathrm{x}$ is $\mathrm{S}_{\mathrm{x}}(\mathrm{t})=$ $\mathrm{l}(\mathrm{x}+\mathrm{t}) / \mathrm{l}(\mathrm{x})$, where the l-function ("survivorship") is the second column of a stan- 
dard life table. Our interest, however, is the case where life expectancy is reduced, and it is no longer obvious how to choose $\mathrm{S}(\mathrm{t})$. The question is whether "rating up," or other commonly used methods for choosing $\mathrm{S}(\mathrm{t})$, yield reasonable estimates of the EPV.

\section{Some Common Approximations for the Survival Distribution}

\section{A. Rating Up}

Rating up is frequently used in life insurance to take account of risk factors such as cigarette and alcohol consumption, obesity, and high blood pressure. An applicant for life insurance is assigned a score according to presence or absence of such factors, and the result is used to determine a "rated age." An applicant who has several risk factors may be rated up several years, meaning that for actuarial purposes he is equivalent to a normal person who is several years older. Rating up is also used to price-structured settlements for lawsuits involving catastrophic injuries.

As an example, consider a boy with severe cerebral palsy who has an agreed upon life expectancy of 20 additional years. The rating-up method identifies the age in the general population at which the life expectancy is likewise 20 years. According to the U.S. Decennial life tables for 1989-91 (National Center for Health Statistics, 1997) this is 58 years, and so the survival probability $\mathrm{S}(\mathrm{t})$ is taken to be that of a normal man of age 58 years. This is inserted into (2.2) and the EPV is computed.

The attraction of the method is that it provides a survival distribution with the correct mean (20 years). The problem is that it is the wrong distribution. As the research literature makes clear (e.g., Hutton et al., 1994), a child with a life expectancy shortened by cerebral palsy is subject to a fairly constant risk over the life span; he may well die in the next few years and also has a reasonable chance of living another 50. By contrast, the man of age 58 is at a relatively low risk over the next few years, but his risk increases steeply over the decades and he has almost no chance of surviving another 50 years. The key point here is that the man of 58 has the same mean survival time as the child with cerebral palsy, but a much smaller variance.

\section{B. Ratio Method}

In the ratio method one multiplies all the age-specific mortality rates in a standard life table by a constant. The constant is chosen to result in the desired life expectancy, and is easily determined by trial and error. The resulting life table then gives the required distribution $\{\mathrm{S}(\mathrm{t})\}$. As we subsequently show, the ratio method yields results, and estimation errors, similar to those derived from rating up. 


\section{Expectancy Method}

In the expectancy method the survival time is simply taken to be exactly equal to the life expectancy. That is, the survival distribution is assumed to be degenerate (i.e., have zero variance). This is the simplest approach and is in consequence very widely used. As we shall see, however, it leads to serious overestimation of the EPV. Informally speaking, the more "tight" the survival distribution around the (fixed) life expectancy, the larger the EPV.

\section{An Empirically Supported Model for the Survival Distribution}

Our empirically based method for constructing a life table for a disabled person proceeds as follows.

A. Estimate a short-term mortality rate.

This can be obtained from the medical literature on survival rates. If a suitable longitudinal database is available, a better approach is to use survival analysis (Collett, 1994) to obtain a survival curve specific to the individual's age, sex, and profile of disabilities. This provides an estimate of mortality rates over the study period, which may be 5 or 10 years.

\section{B. Short-term mortality rates}

These short-term mortality rates may then be extrapolated over the life span, using a suitable model. It has been observed, for example, that age-specific hazard (mortality) rate in many populations (including the general population) roughly follows the Gompertz Law

$$
m(t)=\exp (\tilde{a}+\ddot{a} t),
$$

over the age-range of $30 \leq \mathrm{t} \leq 75$, say. If we denote the general population by the subscript 0 and the disabled group of interest by g, it follows that

$$
\ln \left\{\mathrm{m}_{\mathrm{g}}(\mathrm{t}) / \mathrm{m}_{0}(\mathrm{t})\right\}=\mathrm{a}+\text { ât, }
$$

for some constants á $>0$, $\hat{a}<0$, and a suitable range of ages t. The Gompertz law (4.1) is sufficient, but not necessary, for the model (4.2) to hold.

This "linearly declining log-relative risk" model has received empirical support from data on cerebral palsy (Strauss \& Shavelle, 1998), traumatic brain injury (Strauss \& Shavelle, 1999), and spinal cord injury (Bush et al., 1999). The model implies a parity age, given by -á/â, at which the mortality rate for the disabled group would in theory approximate that of the general population. Empirical estimates of the parity age are 100 years (cerebral palsy, traumatic brain injury), and 118 years (spinal cord injury).

${ }^{2}$ For survival in cerebral palsy see, for example, Hutton, Cooke \& Pharoah (1994); for spinal cord injury see DeVivo \& Ivie (1995) and DeVivo \& Stover (1995); for traumatic brain injury see Strauss, Shavelle \& Anderson (1998). 
Further comparisons suggest that life expectancy estimates derived from (4.2) agree quite closely with the empirically determined life tables. The estimates are generally more accurate than those from the assumptions of constant excess risk or constant relative risk (Strauss \& Shavelle, 1998).

\section{Empirical Comparison of the Methods}

To illustrate the effect of calculating EPV using different procedures, we have constructed Table 1 that presents EPV's for a 5-year-old with life expectancy 20 years who is to receive $\$ 100,000$ for each remaining year of life. The first entry corresponds to no discounting, in which case the EPV is $20 \mathrm{x}$ $\$ 100,000=\$ 2,000,000$, regardless of the form of the survival distribution $\mathrm{S}(\mathrm{t})$.

The remaining entries correspond to a net discount rate of $4 \%$, i.e., the value of a dollar at a future time t years is $1.04^{-\mathrm{t}}$. The second row applies to a hypothetical child who will survive exactly 20 more years-the expectancy method. This leads to the largest possible EPV: $\$ 1,385,947$. The third row is the result of rating up to age 58, which is currently perhaps the most widely used approach. The EPV of $\$ 1,296,538$ is appreciably smaller than the $\$ 1,385,947$ of row 2 . Row 4 is the ratio method: when the mortality rates of a standard life table are all multiplied by 47 the life expectancy for a boy of age 5 years becomes 20 years, and these are the rates used. The resulting EPV of $\$ 1,298,388$ is very similar to that obtained from rating up.

Row 5 gives the EPV for the life table based on the more empirically supported model (4.2). Use of this distribution leads to an EPV of $\$ 1,149,194$. By comparison with this, rating up leads to an EPV that is too high by $\$ 147,344$ (i.e., $13 \%$ ), the ratio method is also too high by $13 \%$, and the "expectancy method" EPV is too high by $21 \%$.

Table 1

Expected Present Values of lifetime care for a 5-year old boy with cerebral palsy. Life expectancy is 20 years, costs are $\$ 100,000$ per year, and a $4 \%$ net discount rate is assumed.

\begin{tabular}{|c|l|l|}
\hline$\#$ & Method & EPV \\
\hline 1. & No discounting at all & $\$ 2,000,000$ \\
\hline 2. & Assuming the child lives exactly 20 years & $\$ 1,385,947$ \\
\hline 3. & "Rating up" (using the life table for a normal male aged 58 years) & $\$ 1,296,538$ \\
\hline 4. & Ratio method & $\$ 1,298,388$ \\
\hline 5. & Using the empirically-based life table & $\$ 1,149,194$ \\
\hline
\end{tabular}

${ }^{3}$ Normally one begins by estimating the short-term hazard rate and then computes all the age-specific rates from equation (4.2). The parameters á and â are determined by the given short-term hazard rate and the known parity age (100 years in the case of cerebral palsy). The resulting life table then provides the life expectancy. For the present example, however, the life expectancy was specified and we carried out the procedure in reverse, identifying the short-term hazard rate (0.0472) that yielded a life table with life expectancy of 20 years. 
Table 2

Expected Present Values of lifetime care for a 25-year old with Traumatic Brain Injury. Life expectancy 20 years, costs $\$ 100,000$ per year, and $4 \%$ net discount rate is assumed.

\begin{tabular}{|c|l|l|}
\hline$\#$ & Method & EPV \\
\hline 1. & No discounting at all & $\$ 2,000,000$ \\
\hline 2. & Assuming the person lives exactly 20 years & $\$ 1,385,947$ \\
\hline 3. & "Rating up" & $\$ 1,296,538$ \\
\hline 4. & Ratio method & $\$ 1,270,161$ \\
\hline 5. & Using the empirically-based life table & $\$ 1,201,977$ \\
\hline
\end{tabular}

Table 3

Expected Present Values of lifetime care for a 25-year old with Traumatic Brain Injury. Life expectancy is 20 years, costs are $\$ 100,000$ per year for the first 20 years and $\$ 200,000$ per year thereafter, and a $4 \%$ net discount rate is assumed.

\begin{tabular}{|c|l|l|}
\hline$\#$ & Method & EPV \\
\hline 1. & No discounting at all & $\$ 2,000,000$ \\
\hline 2. & Assuming the person lives exactly 20 years & $\$ 1,385,947$ \\
\hline 3. & "Rating up" & $\$ 1,446,869$ \\
\hline 4. & Ratio method & $\$ 1,441,194$ \\
\hline 5. & Using the empirically-based life table & $\$ 1,400,688$ \\
\hline
\end{tabular}

Table 2 shows the corresponding results for a 25-year old with traumatic brain injury and a life expectancy of 20 years. The pattern is similar to that of Table 1, although the differences between the rows are less pronounced.

The size of the discrepancy between the various approximate methods and the model (4.2) depends on several factors, of which the most important are the cost schedule $\mathrm{d}(\mathrm{t})$, the discount rate $\mathrm{g}(\mathrm{t})$, and plaintiff's age and life expectancy. In some situations the costs $d(t)$ may increase more rapidly than the discount rate, for example when expensive surgery or personal care are scheduled when the child reaches a certain age. If the product $d(t) g(t)$ is increasing with $t$ in some range, we have a negative net discount rate. In that case the function $h(t)$ in equation (1) is no longer convex, and the EPV from the various approximation methods may or may not exceed the EPV derived from the life table based on (4.2).

One case of the negative net discount rate arises when the cost schedule $\mathrm{d}(\mathrm{t})$ is "lumpy" and the product $\mathrm{d}(\mathrm{t}) \mathrm{g}(\mathrm{t})$ may no longer be a decreasing function. The magnitude and the sign of the discrepancy in the approximated EPV cannot then be predicted. Table 3 corresponds to such a case, a 25-year-old for whom the annual cost will double after 20 years. This may reflect the need for out-of-home care when the parents become too old to provide care.

Tables 4 and 5 show the percentage overestimation of the EPV with the rating-up and ratio methods, respectively. In addition to the case of a 5-yearold with cerebral palsy (Tables $4 \mathrm{a}$ and $4 \mathrm{~b}$ ) we also consider that of a 25-year- 
old yith traumatic brain injury and a life expectancy of 20 years (Tables 5a, $5 b)$. As expected, the amount of overestimation decreases as the net discount rate decreases, and is negative when the net rate is negative. Again, the differences are substantial and the need for an empirically supported life table is clear.

Table 4

Overestimation of Expected Present Value resulting from Rating Up, as a percentage of the EPV based on the empirically supported distribution derived in Section 4.

(a) 5-year old male with cerebral palsy

\begin{tabular}{|c|r|r|r|r|}
\hline & \multicolumn{4}{|c|}{ Net discount rate } \\
\hline Life expectancy & $-3 \%$ & $0 \%$ & $3 \%$ & $6 \%$ \\
\hline 10 & $-12 \%$ & $0 \%$ & $6 \%$ & $10 \%$ \\
\hline 20 & $-23 \%$ & $0 \%$ & $11 \%$ & $15 \%$ \\
\hline 30 & $-25 \%$ & $0 \%$ & $12 \%$ & $15 \%$ \\
\hline 40 & $-22 \%$ & $0 \%$ & $10 \%$ & $12 \%$ \\
\hline 50 & $-16 \%$ & $0 \%$ & $6 \%$ & $7 \%$ \\
\hline
\end{tabular}

(b) 25-year old male with traumatic brain injury

\begin{tabular}{|c|r|r|r|r|}
\hline & \multicolumn{5}{|c|}{ Net discount rate } \\
\hline Life expectancy & $3 \%$ & $0 \%$ & $3 \%$ & $6 \%$ \\
\hline 10 & $-10 \%$ & $0 \%$ & $6 \%$ & $10 \%$ \\
\hline 20 & $-12 \%$ & $0 \%$ & $7 \%$ & $10 \%$ \\
\hline 30 & $-10 \%$ & $0 \%$ & $5 \%$ & $7 \%$ \\
\hline 40 & $-5 \%$ & $0 \%$ & $2 \%$ & $3 \%$ \\
\hline
\end{tabular}

Table 5

Overestimation of Expected Present Value resulting from the Ratio method, as a percentage of the EPV based on the survival distribution derived as in Section 4 .

(a) 5-year old male with cerebral palsy

\begin{tabular}{|c|r|r|r|r|}
\hline & \multicolumn{4}{|c|}{ Net discount rate } \\
\hline Life expectancy & $-3 \%$ & $0 \%$ & $3 \%$ & $6 \%$ \\
\hline 10 & $-14 \%$ & $0 \%$ & $8 \%$ & $12 \%$ \\
\hline 20 & $-22 \%$ & $0 \%$ & $11 \%$ & $15 \%$ \\
\hline 30 & $-22 \%$ & $0 \%$ & $10 \%$ & $13 \%$ \\
\hline 40 & $-19 \%$ & $0 \%$ & $8 \%$ & $10 \%$ \\
\hline 50 & $-14 \%$ & $0 \%$ & $6 \%$ & $7 \%$ \\
\hline
\end{tabular}

(b) 25-year old male with traumatic brain injury

\begin{tabular}{|c|r|r|r|r|}
\hline & \multicolumn{4}{|c|}{ Net discount rate } \\
\hline Life expectancy & $-3 \%$ & $0 \%$ & $3 \%$ & $6 \%$ \\
\hline 10 & $-8 \%$ & $0 \%$ & $4 \%$ & $7 \%$ \\
\hline 20 & $-10 \%$ & $0 \%$ & $5 \%$ & $7 \%$ \\
\hline 30 & $-8 \%$ & $0 \%$ & $4 \%$ & $5 \%$ \\
\hline 40 & $-4 \%$ & $0 \%$ & $2 \%$ & $2 \%$ \\
\hline
\end{tabular}

${ }^{4}$ The construction of the correct life table for a 25 -year-old with traumatic brain injury is analogous to the case of a child with cerebral palsy; again, see Strauss \& Shavelle (1998) for details. 


\section{Discussion}

The expectancy method for calculating the present value of sums related to mortality leads to a significant overestimation except when the net discount rate is close to or less than zero. While some economists are aware of this, it is certainly not widely appreciated in either the economics profession or business community.

The implications of our results are important for both the insurance industry and the legal system. If the methods used for annuity pricing overestimate the present value, insurers may uniformly overprice them. To the extent they are mispriced the result will be a less than optimal supply and demand.

Those concerned with annuity pricing need to take account the possibility of a secular trend: improvements in therapy and medicine for the disabled may result in reduced mortality and thus greater longevity. In view of this, a brief summary of some of the relevant literature may be helpful. In spinal cord injury there has been a steady reduction in mortality over the last few decades, especially in the critical first year post-injury, though this seems to have leveled off in the last 10 years or so (DeVivo \& Stover, 1995; Strauss et al., 2000). The improved survival of ventilator-dependent quadriplegics since the 1970's has been especially dramatic (DeVivo \& Ivie, 1995). In their study of persons in a persistent vegetative state over the last 20 years, Strauss et al. (1999) reported a major drop in infant mortality (age 0-2 years) but did not observe a substantial change for other age groups. Finally, there does not appear to be evidence of major improvements in survival for persons with cerebral palsy; see, for example, Blair et al. (in press).

From a social perspective, if the mortality risk associated with a product is seen to be wrongly assessed this will inhibit the development of new insurance products to meet a greater variety of funding contingencies, such as inflation indexing and shifting payout patterns over time. The lack of a robust and efficient market creates new risks for the disabled, especially that of outliving the funds necessary to care for their medical needs.

With respect to the efficiency of the tort system to provide for damages awards sufficient to meet future needs, current practice usually overstates the true expectation but can also understate it. So long as insurers use improper methods, however, this may not be relevant because the calculations provided to the courts mirror those that are used to price the investment instruments available to the injured. Though that price is not an accurate measure of cost, it nevertheless incorporates the current market price of a specific mortality risk.

Better methods and data are available. Accurate mortality rates specific to an individual's risk factors may be estimated directly from a suitable database. For example, the National Model Spinal Cord Injury Systems database at the University of Alabama at Birmingham contains disability and mortality data on some 40,000 persons with spinal cord injury, and the University of California Life Expectancy group works with a comparable database of some 50,000 persons with cerebral palsy. As a result, it is now possible to estimate a plaintiff's survival function and expected present value of cost of care on a sound scientific basis. 


\section{References}

Ben-Zion, B, and R. Reddall, "Life Expectancy and Actuarial Present Values: A Note To Forensic Economists," Research in Law and Economics, 1985, 7, 161-171.

Blair, E., L. Watson, N. Badawi, and F. J. Stanley, (in press), "Life expectancy among people with cerebral palsy in Western Australia," Developmental Medicine \& Child Neurology.

Bush, R. L., D. J. Strauss, M. J. DeVivo, and R. M. Shavelle, "Life expectancy of persons with spinal cord injury," Technical Report \#265, 1999, Department of Statistics, University of California, Riverside.

Collett, D., Modeling Survival Data in Medical Research, London: Chapman \& Hall, 1994.

DeVivo, M. J., and C. S. Ivie, "Life expectancy of ventilator-dependent persons with spinal cord injuries," Chest, 1995, 108, 226-32.

, and S. L. Stover, "Long-term survival and causes of death," In: S. L. Stover, J. A. DeLisa, and G. G. Whiteneck (Eds.), Spinal Cord Injury, Gaithersburg, MD: Aspen, 1995 , pp. 285-316.

Hutton, J. L., T. Cooke, and P. O. D. Pharoah, "Life expectancy in children with cerebral palsy," British Medical Journal, 1994, 301, 431-435.

Jordan, C. W., Life Contingencies, Second Edition, Chicago: Society of Actuaries, 1967, p. 174.

National Center for Health Statistics (1997). U.S. decennial life tables for 1989-1991, 1997, Volume 1, No. 1. Hyattsville, Maryland: USGPO.

Schoen, R., Modeling multigroup populations, New York: Plenum Press, 1988.

Slesnick, F., and R. J. Thornton, "New Estimates of Life Expectancies For Persons With Medical Risks," Journal of Forensic Economics, Fall 1997, 10(3), 285-290.

Strauss, D. J., and R. M. Shavelle, "Life expectancies of persons with chronic disabilities," Journal of Insurance Medicine, 1998, 30, 96-108.

, and _L_Life tables for people with traumatic brain injury," Journal of Insurance Medicine, 1999, 31, 104-105.

, and S. Ashwal, "Life expectancy and median survival time in the permanent vegetative state," Pediatric Neurology, 1999, 21(3), 626-631.

, and T. W. Anderson, "Long-term survival of children and adolescents after traumatic brain injury," Archives of Physical Medicine and Rehabilitation, 1998, 79, 1095-1100.

ies," Journal of Insurance Medicine, 2000, 32, 217-225. 